\title{
Formation of professional integrated methodological competencies of teachers in an inclusive educational space
}

\author{
O.A. Denisova ${ }^{1 *}$, O.L. Lekhanova ${ }^{2}$, and L.M. Kobrina ${ }^{3}$ \\ ${ }^{1}$ Cherepovets State University, Cherepovets, Russia \\ ${ }^{2}$ Cherepovets State University, Cherepovets, Russia \\ ${ }^{3}$ Pushkin Leningrad State University, Pushkin, Russia
}

\begin{abstract}
The article considers the need for the formation of professional integral methodological competence of teachers in an inclusive educational space. The authors offer qualitative characteristics of formation levels of the studied competence (low, medium, high), describe the structural components of the formation of professional integral methodological competence of teachers in an inclusive educational space. The studied competence will allow teachers to be ready for dynamic changes in the educational process in an inclusive educational space, it will contribute to the intensive accumulation of academic knowledge of children with disabilities and allow to form life competencies and master knowledge, skills and abilities necessary in everyday practice.
\end{abstract}

\section{A problem statement}

For a long time, one of the main concerns of the pedagogical community has been the problem of professional training of teachers in an inclusive education. Analyzing the scientific literature, we can say that interest in inclusive education is reflected in the studies of domestic (S.V. Alekhina [1,2], O.A. Denisova [3], E.V. Ketrishch [4], E.N. Kutepova [5], L.M. Kobrina [6], N.N. Malofeev [7], Yu.V. Melnik [8], O.L. Lekhanova [3], V.V. Khitryuk [9] and others) and foreign authors (Ryndak, D.L., Jackson, L. [10], Shemesh Y.R. [11], N.G. Sigal [12] and others).

The process of formation and development of inclusive education for people with disabilities is regulated by the normative and semantic framework of the current stage of Russian education modernization. The regulatory framework is represented by the Federal Law "On Education" No. 273 (2012) [13], The Concept for the Development of Special and Inclusive Education 2030, the Strategy for the Development of Special and Inclusive Education 2030 [14,15], etc. The semantic framework is set by the existing standards at

\footnotetext{
* Corresponding author: ipcs-profped@yandex.ru
} 
various educational levels: FGOS DET, FGOS NOO, SFGOS NOO HVZ, SFGOS OO UE, Professional Teacher Standard and etc.

All of these documents have defined for the teaching community the characteristics of an inclusive educational space and the range of requirements for a teacher personality in ensuring the appropriate quality of education in this space.

\subsection{The objective of the work}

Methodological approaches to substantiating an inclusive educational space are based on identifying general directions and priorities that determine the choice of pedagogical strategy. The concept of an inclusive educational space is based on the theory of L.S. Vygotsky. In this context, the basic provisions are on the social conditioning of mental development, on the role of pedagogical and socio-cultural influence on the personality formation (L.S. Vygotsky [16], A.V. Petrovsky [17], V.T. Kudryavtsev [18], etc.). In addition, methodological approaches to substantiating an inclusive educational space are based on the theory of personality formation in socially changing conditions (L.P. Bueva [19]) and on adaptation as a process of socialization of a child (L.S. Vygotsky [16], A.V. Mudrik [20]).

The analysis of foreign and domestic literature, as well as inclusive education models, allowed us to present theoretical approaches to defining inclusive education space.

The simulated complex multi-level space of inclusive education must meet the following requirements:

- "continuity", involving the development of the abilities and capabilities of children with disabilities, raising the level of education and qualifications and retraining;

- "accessibility and variability" relying on the zone of proximal and actual development of the child, ensuring his adaptation and individualization;

- "complexity, multi levelness", ensuring constant progress of children with disabilities, presupposing self-realization optimality, self-affirmation of the individual at the stages of socio-cultural integration and inclusion, the productivity of various types of activity;

- "development", aimed at mastering knowledge, skills and abilities that contribute to the full development of the individual;

- "education", involving meeting the spiritual, physical and other socially significant needs of the child;

- "personal self-realization", providing an opportunity to acquire such personality traits that fully characterize its maturity (the ability to independently make decisions, tolerance, autonomy, high moral potential);

- "socialization" providing the conditions for the disabled children activities in the environment development, promoting socio-cultural adaptation, individualization, integration and inclusion;

- "productive interaction" is understood as the central idea of the mechanism of functioning at various levels within the inclusive educational space.

The main functions of the inclusive educational space are the following:

- educational function - provides an increase in the level of education and qualifications of teachers working with children with disabilities in accordance with the changing socioeconomic conditions, the requirements for the education level, needs and capabilities of the person;

- scientific and methodological function - is aimed at a multilevel systematic analysis of the inclusive educational space, its scientific and methodological support, verification of efficiency and improvement at different stages; 
- social function - determines the process of socialization in productive interaction between various subjects of the inclusive educational space, implements the tasks of social protection, social assistance;

- socio-cultural function - ensures the optimization of the cultural level of all subjects of the inclusive educational space as a means of increasing motivation and continuing professional education;

- predictive function - provides predictive development of the educational space, determines the main directions, conditions, factors, adjustment in accordance with changes taking place both outside and inside the space;

- rehabilitation function - implements the rehabilitation component of an inclusive educational space, allows for the comprehensive rehabilitation of the disabled in the process of socio-cultural adaptation and integration;

- the economic function - is to provide jobs and implement a state order for the disabled;

- organizational function - allows forming organizational ties, continuity between different levels, interaction with the external environment.

It is worth highlighting the inclusive educational space signs, which determine its essence. The key features are the unity and integrity of the space, the interconnection and structure of its elements, the openness of the space, and its eventfulness. An important feature of the space is its component composition, which includes both individual and collective subjects characterized by diversity, mobility, openness and structure flexibility. In addition, the inclusive educational space signs include the importance of the space for all stakeholders; content lability; intentional creation and the ability to change; the availability of choice, as well as the competence-based approach in training teachers as subjects of the space and the psychological and pedagogical feasibility of the space.

Thus, based on the sociocultural theory of L.S. Vygotsky, the inclusive educational space means:

- the unity of the place where the process of inclusive practice is carried out;

- filling of educational content, adapted to the individual needs of the child, realizing the goals and objectives of inclusive education;

- barrier-free environment;

- the adequacy of educational influences that ensure the optimal process of inclusion of children with disabilities.

The inclusive educational space unites a number of subspaces (educational organizations and institutions, family, etc.), which makes it possible to define it as complex. An inclusive educational space is multi-level, because it is implemented at different levels (federal, regional, municipal) and includes various components (forming, developing, nurturing and socializing subspaces). All of these structural elements are systematically interconnected, however, depending on the specific conditions for the implementation of goals and objectives, one or another level or component may dominate.

It is important to note that inclusive educational space is an integrated continuous educational system that provides education at all its levels, comprehensive support of the education process in accordance with the objective needs of society, economy, production, as well as requirements for the level of training and competencies of education specialists and social demand, based on the capabilities, needs and interests of the disabled.

The system-forming factor of the inclusive educational space is its target component, which determines the corresponding tasks at several levels: the personality itself, the educational organization, the municipality, the region, the country.

The implementation of an inclusive educational space is possible due to the following conditions: organizational and management, material and technical, scientific and methodological, procedural and technological. The highlighted conditions are closely related and interact. 
One of the most important conditions for the inclusive educational space is the teacher personality who should have a high level of professional competence, including professional integral methodological competence. This competence allows the teacher to be ready for dynamic changes in the educational process in the inclusive educational space, which contributes to the intensive accumulation of academic knowledge of children with disabilities and allows them to form life competencies necessary in everyday practice. The formed competencies of the child will ensure the development of his active relationships with the outside world, being the condition for the assimilation and use of modern achievements of science and practice.

Thus, from our point of view, the formation of integral methodological competence in a modern school can be viewed as a tool for updating the content of education, contributing to the self-realization of the individual and integration into the socio-cultural space.

\section{Materials and the results of the research}

Based on the research results, it can be concluded that the development of a pedagogical modular technology for the formation of professional integral methodological competencies of teachers in the inclusive educational space has been carried out. The article determines the research object as the process of training teachers in the system of vocational education; the subject of research is specified as the formation of professional integral methodological competence of teachers in the inclusive educational space.

Based on the foregoing, we have identified a range of tasks that allows for the formation of professional integral methodological competence:

1. To substantiate and concretize the concept of "formation of professional integral methodological competence".

2. To identify the conditions for the formation of professional integral methodological competence.

3. To substantiate and develop a pedagogical modular technology for the formation of professional integral methodological competence.

The formation of the professional integral methodological competence of teachers in the inclusive educational space was carried out by us in the process of implementing the professional retraining program and advanced training courses.

To substantiate and develop the competence, we used the following approaches: systemic, competence-based, personal, individually differentiated, activity-based.

- Systemic approach allowed determining the leading factors in the formation of professional integral methodological competence of teachers.

- Competence-based approach is aimed at substantiating the features of the structural and content organization of the process.

- Personal approach contributes to the study and understanding of the specific characteristics of the participants in the pedagogical process.

- Individually differentiated approach allows taking into account the existing competencies and tracking the need to fill the missing ones, to carry out input, current and final control on the formation of professional integral methodological competence of the teachers in the learning process as well as to reveal its level.

- Activity-based approach contributes to the implementation of the theoretical knowledge obtained by teachers in practice.

The conditions for the formation of professional integral methodological competence of teachers are as follows:

- the need to include them in various types of activities in the inclusive educational space, which allow solving methodological problems from by the organizers, coordinators, experts and teachers, providing for the exchange and transfer of professional experience; 
productive interaction of all interested subjects of the educational chain: teachers methodological coordinators - supervision from higher education experts - the parental community;

- the obligatory comprehensive methodological support of the teacher at the stage of professional development, which provides for an individual trajectory of mastering professional integral methodological competence through acquiring knowledge and practical skills that contribute to the successful problem solution the inclusive educational space;

- a new meaningful, practice-oriented and structural-organizational program for improving the professional competence of teachers, contributing to the formation of professional integral methodological competence (depending on the educational level of students and their health), analysis of the program material and its adaptation to the modern standard requirements;

- the use of innovative and traditional, filled with new content, practical techniques, methods and technologies of teaching;

- the need to develop an innovative methodological material that meets modern requirements, available for students learning of various levels of perception, storage and processing of information.

The structural components of the formation of professional integral methodological competence of teachers in the inclusive educational space are:

- cognitive component (contributes to the accumulation of special professional knowledge, exchange of advanced teaching experience);

- motivational value component (provides high motivation for competent methodological activity);

- organizational and practical component (aimed at introducing professional integral methodological competence in practice).

The formation of professional integral methodological competence of teachers, in accordance with the requirements of the inclusive educational space, is carried out through mastering pedagogical technology, which is represented by a modular version, including organizational and structural components - informational, operational, efficient, providing special content and phased implementation.

The given above stages characteristics are as follows:

Stage 1: Theoretical.

It differs in the extensive knowledge acquiring by teachers (special pedagogy and psychology; knowledge on general and specific patterns of disabled students' development; peculiarities of perception, storage and processing of information; special methods and technologies of teaching and upbringing; creating special educational conditions for them; using alternative communication, etc.)

Stage 2: Practically oriented.

It represents various ways of mastering professional skills, using available modern resources both in a special educational organization and in implementing inclusive practice.

Stage 3: Professional.

It entails the application of the acquired knowledge in practical activities, where teachers demonstrate the level of forcing of professional integral methodological competence in the inclusive educational space.

The strategy and tactics of implementing the practical knowledge are planned using the developed complex tasks: demonstration material, training exercises, tasks for oral questioning of students, electronic presentations, etc., which increases the variability of working out the material through special lessons: test lesson, control lesson, independent work lesson, practical lesson, research lesson. 
At the same time, the teacher implements various types of activities in practice: diagnostic, correctional, organizational and methodological, consultative and educational, expert.

\section{Conclusions}

The formation of the professional integral methodological competence of teachers in the inclusive educational space can be of different levels: high, medium or low.

The low level of the considered competence is characterized by:

- motivational component (the teacher is not aware of both the significance and value of inclusive education and methodological activities aimed at developing the inclusive educational space);

- cognitive component (the teacher has not formed professional integral methodological competence and inclusive education competence);

- organizational and practical component (professional integral methodological competence is formed at a low level, which does not allow using it in practice, the inclusive culture has not been formed).

The average level of the competence is characterized by:

- motivational component (the teacher is not sufficiently aware of both the importance and value of inclusive education, and methodological activities aimed at developing the inclusive educational space);

- cognitive component (the teacher has insufficiently formed professional integral methodological competence and inclusive education competence);

- organizational and practical component (professional integral methodological competence and inclusive culture are formed at an insufficiently high level, which does not allow using it in practice).

The high level of the studied competence is characterized by:

- motivational component (the teacher highly estimates and realizes both the significance and value of inclusive education and methodological activities aimed at developing the inclusive educational space);

- cognitive component (the teacher has fully formed professional integral methodological competence and inclusive education competence);

- organizational and practical component (professional integral methodological competence is formed at a high level, which enables the teacher to confidently apply it in practice).

Thus, the formation of professional integral methodological competence of teachers in the inclusive educational space is an integrative property of professionally skilled teachers, who determine their readiness and ability to effectively solve methodological problems in the process of disabled students' education in the inclusive educational space, regardless of the severity of developmental disabilities or students' educational level.

\section{References}

1. S.V. Alekhina, Inclusive education and psychological readiness of the teacher, 4 (22), 117-127 (2012)

2. S.V. Alekhina, Psychological and pedagogical research of inclusive education in the practice of training undergraduates, 20 (3), 70-78 (2015)

3. O.A. Denisova, The system of regional special education, p. 272 (Monograph, Vologda, 2008) 
4. E.V. Ketrish, Readiness of the teacher to work in inclusive education, Ekaterinburg, access mode: http://elar.rsvpu.ru/978-5-8050-0653-2

5. E.N. Kutepova, Experience of interaction of special (correctional) and general education in the conditions of inclusive practice, 1, 103-112 (2011)

6. L.M. Kobrin, The domestic system of special education is the foundation of inclusive education and upbringing, 3, 14-19 (2012)

7. N.N. Malofeev, O.S. Nikolskaya, O.I. Kukushkina, E.L. Goncharova, A unified concept of a special federal state standard for children with disabilities: basic provisions, 13, 1 (Moscow, 2009)

8. Yu.V. Melnik, Socio-pedagogical determinants of inclusive education: a comparative analysis of Western and Russian views, 11, 152-162 (2013)

9. V.V. Khitryuk, The teacher's readiness to work with a "special" child: a model of forming the values of inclusive education, 11, $72-79$ (2013)

10. D.L. Ryndak, L.Jackson, \& F. Billingsley, Defining school inclusion for students with moderate to severe disabilities: What do experts say? Exceptionality, 8 (2), 101-116 (2000)

11. Y.R. Shemesh, A survey of teaches perceptions of administrative support and their attitudes toward inclusion in New Jersey, p.40. (Dissertation, 2009)

12. N.G. Segal, Inclusion as a vector of humanization of education and society: foreign experience p. 74 (Kirov, 2014)

13. Federal Law of December 29, 2012 No. 273-FZ "On Education in the Russian Federation", access http://www.consultant.ru/document/cons_doc_LAW_140174

14. Concept for the development of special and inclusive education 2030, access mode: https://school-

4.krn.eduru.ru/media/2019/12/17/1265168834/Strategiya_razvitiya_obrazovaniya_dete j_racii_na_period_do_2030g_proekt.pdf

15. Strategy for the development of special and inclusive education 2030, access mode: https://school-

4.krn.eduru.ru/media/2019/12/17/1265168834/Strategiya_razvitiya_obrazovaniya_dete j_racii_na_period_do_2030g_proekt.pdf

16. L.S. Vygotsky, Collected works: In 6 volumes, 2, 504 (1982-1984)

17. A.V. Petrovsky, V.A. Petrovsky, The individual and his need to "be a person", 3, 4453 (1982)

18. V.T. Kudryavtsev, Psychology of human development. Foundations of the cultural and historical approach, p. 163 (1999)

19. L.P. Buyeva, Social environment and the formation of a harmonious personality, p. 48 (1971)

20. A.V. Mudrik, Education as an integral part of the socialization process, 3 (10), 7-24 (2008) 